\title{
Rice and cold stress: methods for its evaluation and summary of cold tolerance-related quantitative trait loci
}

\author{
Qi Zhang ${ }^{1,2}$, Qiuhong Chen ${ }^{1}$, Shaoling Wang ${ }^{1}$, Yahui Hong ${ }^{1 *}$ and Zhilong Wang ${ }^{1 *}$
}

\begin{abstract}
Cold stress adversely affects rice (Oryza sativa L.) growth and productivity, and has so far determined its geographical distribution. Dissecting cold stress-mediated physiological changes and understanding their genetic causes will facilitate the breeding of rice for cold tolerance. Here, we review recent progress in research on cold stress-mediated physiological traits and metabolites, and indicate their roles in the cold-response network and cold-tolerance evaluation. We also discuss criteria for evaluating cold tolerance and evaluate the scope and shortcomings of each application. Moreover, we summarize research on quantitative trait loci (QTL) related to cold stress at the germination, seedling, and reproductive stages that should provide useful information to accelerate progress in breeding cold-tolerant rice.
\end{abstract}

Keywords: Cold tolerance; Physiological metabolites; Evaluation criteria; QTL; Oryza sativa

\section{Introduction}

Crops are exposed to varied environmental conditions during their life cycle. Cold stress, which can be classified as chilling $\left(0-15^{\circ} \mathrm{C}\right)$ and freezing $\left(<0^{\circ} \mathrm{C}\right)$ stress, is a major environmental factor limiting the growth, productivity, and geographical distribution of crops (Zhu et al. 2007). Rice (Oryza sativa L.), one of the most world's most important staple crops, feeds more than 2.7 billion people worldwide and is extensively grown by more than half of the world's farmers (Fairhurst and Dobermann 2002; Shelton et al. 2002). Due to its origin in tropical and subtropical regions, rice is more sensitive to cold stress than other cereal crops such as wheat (Triticum aestivum L.) and barley (Hordeum vulgare L.). Therefore, in temperate areas, the production of rice is severely limited by cold stress (Xie et al. 2012). Low temperatures that occur at critical reproductive stages can adversely affect grain quality or cause yield reductions in high-latitude or high-altitude regions of China, Japan, Korea, and other parts of the world (Jena et al. 2012).

\footnotetext{
*Correspondence: yahuihong@vip.sina.com; zhilongwang@126.com ${ }^{1}$ Hunan Provincial Key Laboratory of Crop Germplasm Innovation and Utilization, College of Biological Science and Technology, College of Agronomy, Hunan Agricultural University, Changsha, Hunan 410128, China Full list of author information is available at the end of the article
}

Over the past 20 years, extensive efforts have been made to improve cold tolerance in rice, which is a very complex trait (Maruyama et al. 2014). Cold stress affects chlorophyll content and fluorescence, and thus interferes with photosynthesis in rice (Kanneganti and Gupta 2008; $\mathrm{Kim}$ et al. 2009). Moreover, increased contents of reactive oxygen species (ROS) and malondialdehyde (MDA) that accumulate during cold stress in rice can impair metabolism via cellular oxidative damage (Xie et al. 2009; Nakashima et al. 2007). On the other hand, rice also possesses strategies to cope with or adapt to cold stress. For example, cold-treated rice plants accumulate proline, an amino acid that stabilizes protein synthesis, and thereby maintains the optimal function of rice cells (Kandpal and Rao 1985). Under cold stress, contents of antioxidant species also increase to scavenge ROS and protect rice plants against oxidative damage (Sato et al. 2011). Such physiological changes that occur upon cold treatment of rice, whether mediators or symptoms of cold damage, can also be used as indicators to evaluate the cold tolerance of rice.

Due to diverse growing locations and climatic factors, rice cultivars face cold stress at specific growth stages (Saito et al. 2001). Researchers have established many growth-stage specific criteria to evaluate and select cold- 
tolerant rice. Evaluation of rice cultivars typically takes place during seedling and reproductive stages that are critical to production of rice. However, in high-latitude or high-altitude regions, low temperatures during long, cold springs can severely inhibit germination and constrain early seedling growth. So evaluation of cold tolerance at the germination stage is especially significant for these regions.

As the development of molecular markers and linkage maps progresses, marker-assisted selection becomes an effective way to breed cold-tolerant cultivars. Many cold-tolerance related QTL have been identified in the past 20 years. The QTL Ctb1, qCTB2a, qPSST-3, qLTB3 are related to cold tolerance at the reproductive stage; qCTP11 is related to cold tolerance at the germination stage; and $q$ Ctss 11 and $q C T S 4 a$ are related to cold tolerance at the seedling stage. Because breeding for abiotic-stress resistance is urgently needed, progress in the identification of cold tolerance-related QTL has been a significant development for facilitating molecular marker-assisted selection (MAS).

In this review, we focus on clarifying the role of various metabolites during the response to cold stress in rice, and summarize the diverse criteria that are useful for evaluating the cold tolerance of rice at different growth stages. In addition, we discuss QTL and markers related to cold tolerance that can be used to facilitate marker-assisted breeding through recurrent selection in rice.

\section{Review}

\section{Changes in physiological parameters of rice under cold stress}

Low temperature not only inflicts obvious physical damage to rice plants, including low germination rate, stunted seedling growth, high death rate, and low spikelet fertility, but also initiates physiological fluctuations, such as increased electrolyte leakage (EL), changes in chlorophyll fluorescence, and increases in amounts of ROS, MDA, sucrose, lipid peroxidation, proline, and other metabolites. Analysis of metabolites in coldstressed Arabidopsis by gas chromatography-mass spectrometry (GC-MS) has detected a total of 434 lowmolecular-weight carbohydrates, amines, organic acids, and other polar molecules. Of these metabolites, levels of 325 (75\%) had increased, and levels of 114 (35\%) metabolites had increased at least 5-fold upon cold stress (Cook et al. 2004). These metabolites could be organized into six categories related to 1) photosynthesis, 2) electrolyte leakage, 3) ROS and MDA, 4) stress-related soluble sugars, 5) cold-response related amino acids, and 6) antioxidants (Table 1). Thus, changes in the concentrations of these metabolites can be useful indicators for analysis of cold-stress responses in rice.

\section{Chlorophyll content and fluorescence indicate effects of cold stress on photosynthesis}

Chlorophyll content and fluorescence, measured as the ratio of variable fluorescence to maximum fluorescence $\left(\mathrm{F}_{\mathrm{v}} / \mathrm{F}_{\mathrm{m}}\right)$, are two photosynthetic properties whose changes are relevant to cold responses in plants. Chlorophyll content can signify nutrient stress in general, and nitrogen or sulfur stress in particular (Haboudane et al. 2002). Cold stress can inhibit chlorophyll synthesis and chloroplast formation in rice leaves. Thus, reduced chlorophyll content can indicate the effect of low temperature on rice plants (Sharma et al. 2005).

$\mathrm{F}_{\mathrm{v}} / \mathrm{F}_{\mathrm{m}}$ is a measure of chlorophyll fluorescence that is commonly used to determine the maximum quantum efficiency of Photosystem II (PSII), which indicates whether cold stress has compromised PSII in its darkadapted state (McFarlane et al. 1980). During cold stress, $\mathrm{F}_{\mathrm{v}} / \mathrm{F}_{\mathrm{m}}$ values decrease slightly in plants that tolerate cold, but decrease significantly in plants that are sensitive to cold (Bonnecarrère et al. 2011; Zahedi and Alahrnadi 2007). This parameter is thus useful for assaying the cold tolerance and sensitivity of plants that differ for this trait due either to genetics or acclimation.

The expression of several genes known to be involved in stress signal transduction can influence chlorophyll content or fluorescence. For example, chlorophyll content is much higher compared to that of control plants in both rice and tobacco transgenic lines overexpressing OsiSAP8, a member of the SAP gene family in rice. Osi$S A P 8$ encodes a cytoplasmic zinc finger protein that acts early in the signal transduction of responses to various stresses including cold (Kanneganti and Gupta 2008).

Additionally, ectopic expression of another coldresponsive gene, OsAsr 1, which functions in abscisic acid (ABA)-response and fruit ripening, results in twofold higher values for $F_{v} / F_{m}$ in transgenic rice seedlings, a finding consistent with enhanced cold tolerance (Kim et al. 2009). The phytohormone ABA is involved in various aspects of plant growth and development, and one of its major roles is to mediate adaptive responses to various environmental stresses (Hossain et al. 2010b). In cold-stressed rice, ABA accumulates and initiates the ABA signaling cascade, which affects the expression of ABA-responsive genes via cis-acting ABA-response elements (ABRE) and the ABRE-binding bZIP transcription factor (ABF) (Hossain et al. 2010a). The OsNAC gene transduces the ABA signal through an ABRE in its promoter and regulates the expression of NACRS-containing genes to control cold tolerance in rice (Figure 1A) (Nakashima et al. 2012; Nakashima et al. 2007; Song et al. 2011).

Yamburenko reported that exogenous ABA reduced chlorophyll content and differentially affected the expression of chloroplast genes, suggesting a role of ABA in the regulation of proteins with functions in photosynthesis in 
Table 1 Changes in metabolic properties of rice plants during cold stress

\begin{tabular}{|c|c|c|c|}
\hline $\begin{array}{l}\text { Group and } \\
\text { property }\end{array}$ & $\begin{array}{l}\text { Effect on } \\
\text { tolerance }\end{array}$ & Relevant gene & Reference \\
\hline \multicolumn{4}{|l|}{ Photosynthesis } \\
\hline $\begin{array}{l}\text { Chlorophyll } \\
\text { content }\end{array}$ & Positive & OSISAP8, TERF2 & (Kanneganti and Gupta 2008; Tian et al. 2011) \\
\hline $\mathrm{Fv} / \mathrm{Fm}$ & Positive & CBF1/DREB1b, Asr1, OsCDPK7 & (Kim et al. 2009; Lee et al. 2004; Saijo et al. 2001) \\
\hline $\begin{array}{l}\text { Electrolyte } \\
\text { leakage }\end{array}$ & Negative & $\begin{array}{l}\text { CBF1/DREB16, OsLti6, ZFP245, TERF2, OVP1, } \\
\text { OsNAC5 }\end{array}$ & $\begin{array}{l}\text { (Huang et al. 2009; Tian et al. 2011; Song et al. 2011; Zhang et al. } \\
2011 \text { a; Lee et al. 2004; Morsy et al. 2005) }\end{array}$ \\
\hline \multicolumn{4}{|l|}{ ROS and MDA } \\
\hline $\begin{array}{l}\text { Hydrogen } \\
\text { peroxide }\end{array}$ & Negative & $\begin{array}{l}\text { OsAPXa, OsMKKG, OsMPK3, OsNAC6, } \\
\text { OsTRX23, SodCc1, OsPOX1 }\end{array}$ & $\begin{array}{l}\text { (Xie et al. 2012; Xie et al. 2009; Sato et al. 2011; Lee et al. 2009; } \\
\text { Nakashima et al. 2007) }\end{array}$ \\
\hline $\begin{array}{l}\text { Superoxide } \\
\text { radicals }\end{array}$ & Negative & OsAPXa & (Sato et al. 2011) \\
\hline Hydroxyl radicals & Negative & OsAPXa & (Sato et al. 2011) \\
\hline Malondialdehyde & Negative & $\begin{array}{l}\text { OsAPXa, OsMKKG, OsMPK3, OsNAC6, } \\
\text { ZmCBF3 }\end{array}$ & (Sato et al. 2011; Xie et al. 2012; Xu et al. 2011; Nakashima et al. 2007) \\
\hline \multicolumn{4}{|l|}{ Soluble sugars } \\
\hline Sucrose & Positive & OSINV4, OsDREBTA, TERF2 & (Tian et al. 2011; Oliver et al. 2005; Ito et al. 2006) \\
\hline Hexose & Positive & OSINV4 & (Oliver et al. 2005) \\
\hline Raffinose & Positive & OsDREB1A, TERF2 & (Tian et al. 2011; Ito et al. 2006) \\
\hline Glucose & Positive & OsDREB1A, TERF2 & (Tian et al. 2011; Ito et al. 2006) \\
\hline Fructose & Positive & OsDREB1A, TERF2 & (Tian et al. 2011; Ito et al. 2006) \\
\hline Trehalose & Positive & OsNAC5, OsPP1, OsPP2, OsTPP & (Song et al. 2011) \\
\hline \multicolumn{4}{|l|}{$\begin{array}{l}\text { Cold-related } \\
\text { amino acids }\end{array}$} \\
\hline Proline & Positive & $\begin{array}{l}\text { OsCOIN, OsDREB1A, OsMYB2, OVP1, } \\
\text { OsNAC5, MYB4, OsPRP3, ZFP245, OsMYB3R-2 }\end{array}$ & $\begin{array}{l}\text { (Huang et al. 2009; Tian et al. 2011; Song et al. 2011; Zhang et al. 2011a; } \\
\text { Liu et al. 2007; Yang et al. 2012; Vannini et al. 2004; Gothandam et al. 2010; } \\
\text { Ma et al. 2009) }\end{array}$ \\
\hline \multicolumn{4}{|l|}{ Antioxidants } \\
\hline Ascorbic acid & Positive & Unknown & (Kim and Tai 2011) \\
\hline Glutathione & Positive & OsTRX23 & (Kim and Tai 2011; Xie et al. 2009) \\
\hline
\end{tabular}

barley leaves (Yamburenko et al. 2013). However, in rice, the role of ABA in regulation of photosynthesis-related genes has not yet been fully explained. Therefore, progress in this field will help to bridge the gaps in our knowledge of the crosstalk between cold stress, ABA signaling, and photosynthesis.

\section{Changes in membrane fluidity initiate cellular cold responsive}

Changes in ambient temperature can affect cell membranes quickly, although this is a reversible process (Murata and Los 1997; Los and Murata 2004; Sangwan et al. 2002). Changes in membrane fluidity are measured by the membrane polarization index, $p$, an inverse indicator of membrane fluidity (Sangwan et al. 2002).

Rice cells can sense cold stress based on changes in membrane rigidity, the physical state of membrane proteins, and osmotic pressure (Los and Murata 2004). Low temperatures initiate increased membrane rigidity and can lead to increased EL, which can indicate the activity of cold tolerance-relevant genes, including TERF2, OVP1, and OsNAC5 (Yun et al. 2010; Tian et al. 2011; Zhang et al. 2011a; Song et al. 2011). Functional characterization of the cold-activated Stress-activated MAPK (SAMK) reveals that a MAPK signaling cascade is triggered by increased membrane rigidity and altered ion conductance within cells and tissues (Sangwan et al. 2002). Also, the influx of $\mathrm{Ca}^{2+}$ into the cytoplasm, an early event in cold stress, may be mediated by $\mathrm{Ca}^{2+}$ channels that are activated by membrane rigidification, ligands, or mechanical stimuli (Chinnusamy et al. 2006). This cold-sensing signal can be interpreted and amplified by a calcium signaling cascade that subsequently activates the DREB-CRT/DRE (dehydration-responsive element-binding proteins-Crepeat/dehydration-responsive elements) pathway in rice (Zhang et al. 2013), which is an important cascade for cold sensing and response in rice (Figure 1B) (Zhu et al. 2007; Chinnusamy et al. 2007). 

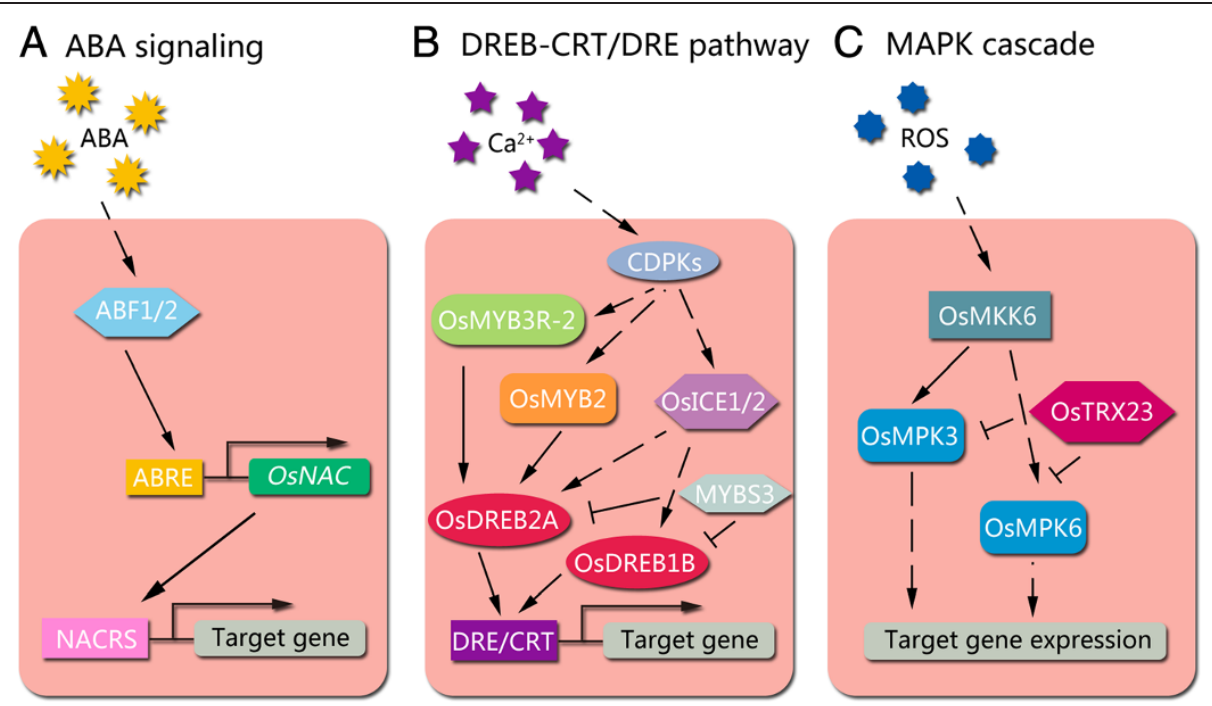

Figure 1 Cold sensing and responsive pathway in rice. (A) ABA signaling is initiated by ABA accumulation, and is transduced by $A B F$ and the ABRE-containing OSNAC gene, which regulates the expression of a NACRS-containing target gene to increase cold tolerance. (B) The DREB-CRT/ DRE pathway is initiated by a $\mathrm{Ca}^{2+}$-influx signal that is transduced by calcium-dependent protein kinases (CDPKs), OsMYB3R-2, OsMYB2, and OsICE1/2. The expression of OsDREB1B and OsDREB2A are down-regulated by MYBS3. (C) The MAPK cascade (OsMKK6-OsMPK3 and OsMPK6) is activated by ROS and is negatively regulated by OsTRX23. Solid arrows indicate direct activation; broken arrows indicate indirect activation; lines ending with a bar indicate negative regulation.

\section{ROS and MDA mediate cold damage and cold sensing in rice}

ROS are chemically reactive molecules that contain oxygen, including superoxide $\left(\mathrm{O}_{2}^{-}\right)$, hydrogen peroxide $\left(\mathrm{H}_{2} \mathrm{O}_{2}\right)$, or the hydroxyl radical $\left(\mathrm{HO}^{-}\right)$that are produced at low levels as normal byproducts of plant cellular metabolism, mainly in organelles such as chloroplasts, mitochondria, and peroxisomes. However, both biotic and abiotic stresses can lead to excessive production of ROS that can then react rapidly with proteins, DNA, and lipids to cause cellular oxidative damage (Apel and Hirt 2004; Skopelitis et al. 2006; Mittal et al. 2012).

In chloroplasts, ROS may cause over-reduction of the electron transport chain, limit $\mathrm{CO}_{2}$ fixation, and interfere with the photosynthetic process. ROS can also cause damage during stress through their effects upon the electron transport chain in mitochondria (Suzuki and Mittler 2006). ROS degrade polyunsaturated lipids to form MDA, a reactive aldehyde that initiates toxic stress in cells and subsequently causes cellular dysfunction and tissue damage (Pamplona 2011). In a study evaluating QTL associated with cold tolerance, elevated MDA content $\left(0.00-0.57 \mathrm{nmol} \mathrm{g}^{-1} \mathrm{FW}\right)$ was found in $92.16 \%$ (47/ 51) of rice cultivars (Kim and Tai 2011). Other studies have revealed that the accumulation of ROS in cells of cold-treated rice triggers expression of cold-responsive genes and regulation of the cold-responsive signaling network via the OsMKK6-OsMPK3 (MAPKK-MAPK) pathway (Figure 1C) (Xie et al. 2009).

\section{Soluble sugars, proline, and antioxidants protect rice from further damage due to cold stress}

Soluble sugars that accumulate in plants under stress include sucrose, hexose, raffinose, glucose, fructose, and trehalose. These sugars act as compatible solutes in freezing stress, serving as osmoprotectants against freezing-dehydration damage (Nagao et al. 2005; Shao et al. 2007; Yuanyuan et al. 2010). Because sucrose, trehalose, raffinose, and stachyose contents can increase under low temperature, these metabolites can be used as indicators to evaluate the potential cold tolerance of rice varieties (Morsy et al. 2007).

Moreover, proline accumulation is also enhanced by cold stress. In addition to acting as a reservoir of carbon and nitrogen, proline also protects cellular enzymes from denaturation (Shah and Dubey 1997). Proline stabilizes the polyribosome and thereby maintains the operation of protein synthesis (Kandpal and Rao 1985). Proline is also involved in removal of stress-related excess $\mathrm{H}^{+}$and maintains oxidative respiration at optimal cytosolic pH (Venekamp 1989). Moreover, proline increases protein water-binding ability through its hydrophobic interactions with the surface residues of proteins (Schobert and Tschesche 1978). Increased proline content has been widely observed in rice varieties under low temperatures. Finally, the significant correlations between proline contents and cold tolerance have help to confirm the function of proline during the cold response in rice (Kim and Tai 2011). 
In another metabolic adaptation, antioxidant species scavenge ROS to protect rice plants against oxidative damage induced by cold stress. These antioxidant species include ascorbic acid (AsA) and glutathione (GSH) (Kim and Tai 2011; Xie et al. 2009). Such antioxidants occur at high concentrations in chloroplasts and other cellular compartments, and are crucial for defense of plants against oxidative stress (Noctor and Foyer 1998; Mittler 2002). Sato reported that overexpression of OsAPXa, an ascorbate peroxidase gene, improves cold tolerance by increasing ascorbate peroxidase activity to reduce the levels of $\mathrm{H}_{2} \mathrm{O}_{2}$ and lipid peroxidation under cold stress (Sato et al. 2011).

\section{Current criteria for the evaluation of cold tolerance in various rice cultivars}

Evaluation of rice cultivars for improved cold tolerance is mainly performed during the seedling and reproductive stages. Cold tolerance at the germination stage is a significant component of rapid seedling establishment and development of a uniform crop stand, especially in direct-seeding production systems (Krishnasamy and
Seshu 1989). Because rice is cultivated in regions that range from tropical to temperate, considerable variation in the extent of cold tolerance is exhibited by seedlings of various $O$. sativa germplasm accessions (Kim and Tai 2011; Sharifi 2010). So evaluation of cold tolerance at the seedling stage is important for adaptation to highaltitude or high-latitude locations that can experience cold temperatures at night or early or late in the growing season. Finally, cold tolerance during reproductive stages is critical for pollen survival, seed set, and grain filling to ensure maximal yield (Suh et al. 2010). Criteria for the evaluation of cold tolerance in rice at different growth stages are summarized in Table 2 and described in detail below.

\section{Evaluation of cold tolerance in rice at the germination stage}

Germination vigor and seedling survival rate are the two main criteria used for the evaluation of cold tolerance in rice at the germination stage. The vigor of seed germination is recorded at $7 \mathrm{~d}, 11 \mathrm{~d}, 14 \mathrm{~d}$, and $17 \mathrm{~d}$ following germination at $14^{\circ} \mathrm{C}$ in the dark.

Table 2 Current criteria for evaluation of cold tolerance in rice at different growth stages

\begin{tabular}{|c|c|c|c|c|}
\hline \multirow[t]{2}{*}{$\begin{array}{l}\text { Evaluation } \\
\text { criteria }\end{array}$} & \multirow[t]{2}{*}{ Description } & \multicolumn{2}{|c|}{$\begin{array}{l}\text { Temperature and } \\
\text { duration }\end{array}$} & \multirow[t]{2}{*}{ Reference } \\
\hline & & Treatment & Recovery & \\
\hline \multicolumn{5}{|l|}{$\begin{array}{l}\text { Germination } \\
\text { stage }\end{array}$} \\
\hline $\begin{array}{l}\text { Vigor of } \\
\text { germination }\end{array}$ & $\begin{array}{l}\text { Vigor of germination }(\%)=\text { Number of germinated grains/Number of } \\
\text { total grains } \times 100\end{array}$ & $\begin{array}{l}14^{\circ} \mathrm{C} / 7-17 \\
\mathrm{~d}\end{array}$ & - & (Han et al. 2006) \\
\hline $\begin{array}{l}\text { Seedling } \\
\text { survival rate }\end{array}$ & $\begin{array}{l}\text { Seedling survival rate }(\%)=\text { Surviving seedlings/Sprouting seeds } \times \\
100 \text {, determined when shoots are about } 5 \mathrm{~mm} \text { long. }\end{array}$ & $2^{\circ} \mathrm{C} / 3 \mathrm{~d}$ & $20^{\circ} \mathrm{C} / 7 \mathrm{~d}$ & (Zhou et al. 2012) \\
\hline \multicolumn{5}{|l|}{$\begin{array}{l}\text { Seedling } \\
\text { stage }\end{array}$} \\
\hline $\begin{array}{l}\text { Fresh weight } \\
(\text { FW) }\end{array}$ & $\begin{array}{l}\text { Changes in FW of plants after cold treatment can be used as an } \\
\text { indicator of cold damage. }\end{array}$ & $\begin{array}{l}10^{\circ} \mathrm{C} / 1- \\
48 \mathrm{~h}\end{array}$ & - & (Bonnecarrère et al. 2011) \\
\hline Survival rate & $\begin{array}{l}\text { Survival rate }(\%) \text { after cold treatment is calculated as the Number of } \\
\text { surviving plants/Total number plants treated } \times 100\end{array}$ & $4^{\circ} \mathrm{C} / 6 \mathrm{~d}$ & $26^{\circ} \mathrm{C} / 6 \mathrm{~d}$ & (Zhang et al. 2011b) \\
\hline $\begin{array}{l}\text { Leaf } \\
\text { emergence }\end{array}$ & $\begin{array}{l}\text { New leaf emergence demonstrates maintained vigor and increased } \\
\text { growth. }\end{array}$ & $4^{\circ} \mathrm{C} / 7 \mathrm{~d}$ & $25^{\circ} \mathrm{C} / 10 \mathrm{~d}$ & (Xie et al. 2012) \\
\hline $\begin{array}{l}\text { Seedling } \\
\text { growth }\end{array}$ & $\begin{array}{l}1=\text { dark green seedlings, } 3=\text { light green seedlings, } 5=\text { yellow } \\
\text { seedlings, } 7=\text { brown seedlings, } 9=\text { seedlings dead. }\end{array}$ & $9^{\circ} \mathrm{C} / 8-14 \mathrm{~d}$ & - & $\begin{array}{l}\text { (Kim and Tai 2011; IRRI 2002; Andaya } \\
\text { and Tai 2006) }\end{array}$ \\
\hline Leaf growth & $\begin{array}{l}\text { A score of 1-3 (tolerant, all leaves normal, no apparent visual injury), } \\
\text { or 4-9 (susceptible, all leaves wilted, seedlings apparently dead). }\end{array}$ & $10^{\circ} \mathrm{C} / 7 \mathrm{~d}$ & $25^{\circ} \mathrm{C} / 7 \mathrm{~d}$ & (Suh et al. 2012) \\
\hline $\begin{array}{l}\text { Metabolic } \\
\text { assessments }\end{array}$ & Metabolites include EL, proline, MDA, and AsA, and GSH. & $9^{\circ} \mathrm{C} / 1-14 \mathrm{~d}$ & - & $\begin{array}{l}\text { (Tian et al. 2011; Zhang et al. 2011a; } \\
\text { Kim and Tai 2011; Yang et al. 2012) }\end{array}$ \\
\hline $\begin{array}{l}\text { Enzyme } \\
\text { activities }\end{array}$ & Enzymes include POD, SOD, and CAT, and APX. & $4^{\circ} \mathrm{C} / 0-4 \mathrm{~d}$ & $25^{\circ} \mathrm{C} / 7 \mathrm{~d}$ & $\begin{array}{l}\text { (Bonnecarrère et al. 2011; Huang } \\
\text { et al. 2009; Sato et al. 2001) }\end{array}$ \\
\hline \multicolumn{5}{|l|}{$\begin{array}{l}\text { Reproductive } \\
\text { stage }\end{array}$} \\
\hline $\begin{array}{l}\text { Spikelet } \\
\text { fertility (CGC) }\end{array}$ & $\begin{array}{l}\text { Spikelet fertility is calculated as the ratio of filled grains to the total } \\
\text { number of florets, basing on cold greenhouse cultivation. }\end{array}$ & $12^{\circ} \mathrm{C} / 6 \mathrm{~d}$ & $\begin{array}{l}\text { Until } \\
\text { maturation }\end{array}$ & (Sato et al. 2011) \\
\hline $\begin{array}{l}\text { Spikelet } \\
\text { fertility (CDWI) }\end{array}$ & $\begin{array}{l}\text { Spikelet fertility is calculated as the same as spikelet fertility (CGC), } \\
\text { but the cold treatment is based on cold deep-water irrigation. }\end{array}$ & $\begin{array}{l}18-19^{\circ} \mathrm{Cl} \\
\sim 60 \mathrm{~d}\end{array}$ & - & (Shirasawa et al. 2012) \\
\hline
\end{tabular}


Germination vigor $(\%)=($ Number of germinated grain/ Number of total grain) $\times 100$.

The standard assessment of whether a rice grain has germinated is determined as the point at which the bud length equals half the length of the seed, and the root length equals the seed length (Han et al. 2006).

The seedling survival rate for cold tolerance is evaluated as follows. When shoots are about $5 \mathrm{~mm}$ long, the germinated seedlings are planted in soil and are subjected to cold treatment at $2^{\circ} \mathrm{C}$ for $3 \mathrm{~d}$, and are then moved to a sunny indoor environment where the temperature is above $20^{\circ} \mathrm{C}$ to ensure normal growth. Seedling survival rates are assessed after $7 \mathrm{~d}$ recovery growth and cold tolerance evaluation indices are calculated as:

Seedling survival rate $(\%)=$ surviving seedlings/budding seeds $\times 100$ (Zhou et al. 2012).

During cultivation, rice seeds are germinated in early spring at the appropriate temperature (usually $32^{\circ} \mathrm{C}$ ), and the germinated seeds are then sown in the field when the shoots are approximately $5 \mathrm{~mm}$ long. Thus, rice seedlings are more likely to encounter cold stress after sprouting than during germination. Therefore, seedling survival rate (\%) is a more practical criterion for the evaluation of cold tolerance than are traits that are assessed at the germination stage.

\section{Evaluation of cold tolerance in rice at the seedling stage}

Both visual and physiological indicators are used to evaluate cold tolerance at the seedling stage in rice. Five criteria are typically used for visual assessment of cold tolerance, including fresh weight, survival rate, new leaf emergence, seedling growth, and leaf growth.

As water loss often occurs concomitantly with plant damage, changes in fresh weight can be used to indicate water loss and growth retardation of rice plants under cold stress (Bonnecarrère et al. 2011). However, water loss is not always an accurate indicator of cold stress because it can also be affected by traits including plant variety and leaf size, and also by other stressors.

The survival rate (\%) (the number of surviving plants divided by the total number of plants treated $\times 100$ ) is determined after $4^{\circ} \mathrm{C}$ treatment, which is a severe condition for rice growth that explicitly distinguishes the cold tolerance of cultivars in short time periods ranging from 6 to $7 \mathrm{~d}$ (Zhang et al. 2011b). As this method clearly and efficiently distinguishes degrees of cold tolerance among cultivars and individuals, it is recommended for gauging cold tolerance in the laboratory. Moreover, new leaf emergence can also be used to assess cold tolerance in transgenic rice in terms of maintained vigor and increased growth (Xie et al. 2012). For some cold-tolerant wild type plants and their transgenic lines, cold stress $\left(4^{\circ} \mathrm{C}\right.$ treatment) only retards growth rather than causing lethal damage. So, new leaf emergence would be a better choice for distinguishing the cold tolerance of these lines.

The seedling growth scale is derived from the standard evaluation system for rice that was developed by the International Rice Research Institute (IRRI 2002). After $14 \mathrm{~d}$ of cold treatment at $9^{\circ} \mathrm{C}$, this assay is performed by scoring seedlings as $1=$ dark green seedlings, $3=$ light green seedlings, $5=$ yellow seedlings, $7=$ brown seedlings, $9=$ dead seedlings (Kim and Tai 2011; Andaya and Tai 2006). Using a similar visual scaling approach, the leaf growth scale is based on the degree of leaf wilting and is scored on a scale of 1-3 (tolerant, all leaves normal, no apparent visual injury) to 4-9 (susceptible, all leaves wilted, seedlings apparently dead) (Suh et al. 2012). However, unlike the seedling growth scale, in which seedlings are examined immediately after low temperature treatment, the leaf growth assay is based on symptoms that are apparent on the 7th day of the recovery period (Suh et al. 2012). Because of the moderate treatment $\left(9-10^{\circ} \mathrm{C}\right)$, the seedling growth scale and leaf growth assay are often used to show minor differences in cold tolerance between cultivars. Moreover, because the recovery period at $25^{\circ} \mathrm{C}$ lasts $7 \mathrm{~d}$, the leaf growth assay can better distinguish cultivars with similar cold tolerance than can the seedling growth scale.

As visual ratings are limited by their tendency to be subjective, physiological parameters thus complement the evaluation of cold tolerance in rice. These parameters include measurements of EL, proline, MDA, AsA, and GSH (Tian et al. 2011; Zhang et al. 2011a; Yang et al. 2012), changes in which can be attributed to coldresponsive metabolism. For example, temperate $O$. japonica varieties exhibit less EL, while $O$. indica varieties tend to accumulate higher levels of proline, MDA, AsA, and GSH (Kim and Tai 2011). The differences in these physiological parameters also indicate the relative degrees of cold tolerance among rice cultivars. Moreover, because MDA is related to the accumulation of ROS, the examination of MDA can indicate whether the cold tolerance in transgenic lines is related to ROS signaling.

In addition, activities of antioxidant enzymes such as peroxidase (POD), superoxide dismutase (SOD), catalase (CAT), and ascorbate peroxidase (APX) can also be used to evaluate cold tolerance in rice. The higher activities of antioxidant enzymes often expressed in transgenic rice lines can indicate their relatively improved cold tolerance compared to wild-type plants (Bonnecarrère et al. 2011; Huang et al. 2009). Increased activities of antioxidant enzyme, including OsPOX1, APXa, and related kinase OsTrx23 (Kim et al. 2011; Sato et al. 2011; Xie et al. 2012) may serve to maintain the functions of many other genes during cold stress. Therefore, rather than only physical evaluation of whole-plant cold tolerance, evaluation of antioxidant enzyme activities could both reveal cold- 
tolerant plants and reveal the mechanisms of cold tolerance.

\section{Evaluation of cold tolerance in rice at the reproductive stage}

Exposure to low temperatures during the reproductive stage in rice can cause male sterility and thereby severe yield loss. Cold tolerance at this stage can be evaluated by spikelet fertility based on cold greenhouse cultivation (CGC) or cold deep-water irrigation (CDWI).

To obtain synchronously developing panicles for calculating spikelet fertility using $\mathrm{CGC}$, extra tillers are removed from each greenhouse-grown $\left(26^{\circ} \mathrm{C} / 19^{\circ} \mathrm{C}\right.$ day/ night temperature regime) plant at the tillering stage, leaving the main culm. Pollen development is estimated using the auricle distance method (Satake and Hayase 1970). When the auricle of the flag leaf is approximately $5 \mathrm{~cm}$ below the auricle of the penultimate leaf on each plant, the pollen should have undergone meiosis, and each pot is then transferred to a greenhouse maintained at $12^{\circ} \mathrm{C}$. After 5-6 d, the cold-treated pots are returned to the warmer greenhouse, where they remain until the plants reach maturity (Andaya and Mackill 2003b; Suh et al. 2010). At heading, each plant is tagged with the heading date to verify the developmental stage that pollen had reached after cold treatment, then mean spikelet fertility is calculated for the evaluation of cold tolerance (Sato et al. 2011).

Spikelet fertility can also be assessed after cold treatment by CDWI. When young panicles begin to differentiate, rice plants are transferred to tanks filled to 20$25 \mathrm{~cm}$ depth with water maintained at $18-19^{\circ} \mathrm{C}$. Plants are maintained in the cold deep-water irrigation tanks during the entire booting stage. Spikelet fertility is calculated based on the percentage of the number of fertile grains relative to the number of florets (Shirasawa et al. 2012). Spikelet fertility using CDWI was developed to examine the cold tolerance of rice accessions about 30 years ago, and it is still widely used for selecting coldtolerant lines because it is highly reliable (Matsunaga 2005; Shimono et al. 2011; Shirasawa et al. 2012).

Both of these methods can be used to select more coldtolerant rice varieties. Compared to CGC, CDWI exposes plants to a more moderate treatment temperature and a longer treatment period, and is conducted directly in field. Therefore, CDWI is more suitable for distinguishing the cold tolerance of relatively cold-sensitive cultivars and for evaluating the cold tolerance of QTL mapping populations.

\section{QTL identified in various cultivars facilitate the breeding of cold-tolerant rice}

Cold tolerance in rice is a quantitative trait controlled by multiple genes. Because it is often difficult to directly associate plant phenotypes with the genes responsible for cold tolerance, marker-assisted selection is an effective means of developing cold-tolerant cultivars (Shirasawa et al. 2012; Foolad et al. 1999). The development of molecular markers and linkage maps has made it possible to identify QTL that control cold tolerance in rice (Table 3). QTL analyses have been carried out using rice populations with large levels of genetic variation for cold tolerance (Futsuhara and Toriyama 1969).

\section{QTL related to cold tolerance at the germination stage}

A set of $\mathrm{F}_{2: 3}$ populations including 200 individuals and lines derived from a cross between the indica and japonica varieties 'Milyang 23' x 'Jileng 1' was used to locate QTL for low-temperature vigor of germination (LVG) and to develop a cold-response index for vigor of germination (CIVG). In that study, the QTL qLVG2 was detected in the region of RM29-RM262 on chromosome 2, and $q L V G 7-2$ and $q$ CIVG7-2 were mapped to the region near RM336-RM118 on chromosome 7 (Han et al. 2006). A major QTL for low temperature germination ability, qLTG3-1, was identified by Fujino on chromosome 3 using backcross inbred lines (BIL) derived from a cross between 'Italica Livorno' and 'Hayamasari' (varieties with vigorous or weak low-temperature germination ability, respectively) (Fujino et al. 2008). This QTL explains $30 \%$ of the total phenotypic variation for lowtemperature germination in their mapping population and was thought to be involved in tissue weakening, a key process during seed germination.

Two major QTL ( $q$ CTP11 and $q C T P 12$ ) for cold tolerance at the plumule stage were identified in genetic stocks derived from 34 cultivated (Oryza sativa) and 23 wild (Oryza rufipogon) rice strains (Baruah et al. 2009). Both tropical and temperate japonica subpopulations, and also annual, intermediate, and perennial O. rufipogon types were used for this study (Vaughan et al. 2003). Cold tolerance was scored based on vigor of germination. In another study, cold tolerance at the bud burst stage (CTB) was evaluated at $5^{\circ} \mathrm{C}$ in a set of 95 chromosome-segment substitution lines (CSSL), derived from indica rice accession 9311 and japonica rice cultivar 'Nipponbare', which has the genetic background of 9311. In this study, QTL $q C T B-5-1, q C T B-5-2$, and $q C T B-5-3$ were mapped in the regions of RM267RM1237, RM2422-RM6054, and RM3321-RM1054, respectively, at positions $21.3 \mathrm{cM}, 27.4 \mathrm{cM}$, and $12.7 \mathrm{cM}$ on rice chromosome 5. Additionally, the QTL $q C T B-7$ mapped to a $6.8-\mathrm{cM}$ region near RM11-RM2752 on rice chromosome 7 (Lin et al. 2010).

\section{QTL related to cold tolerance at the seedling stage}

A set of recombinant inbred lines (RIL) that were derived from a cross between M202 and IR50 (indica, highly sensitive to cold stress) was used to identify QTL conferring tolerance to cold stress at the seedling stage. 
Table 3 QTL associated with cold tolerance in rice

\begin{tabular}{|c|c|c|c|c|}
\hline Name of QTL & Year & Trait for mapping & Chromosome no. & Reference \\
\hline$C+b 1, C+b 2$ & 2001 & Spikelet fertility/Undeveloped spikelet & 4 & (Saito et al. 2001) \\
\hline qСТВ2a, qCTB3 & 2003 & Spikelet fertility/Undeveloped spikelet & 2,3 & (Andaya and Mackill 2003b) \\
\hline aCTS12a & 2003 & Seedling growth & 12 & (Andaya and Mackill 2003a) \\
\hline Ctb1 & 2004 & Spikelet fertility & 4 & (Saito et al. 2004) \\
\hline Dth, $c l, f e r, p e, d c$ & 2004 & $\begin{array}{l}\text { Days to heading/Culm length/Spikelet fertility/ } \\
\text { Panicle neck exsertion/Discoloration }\end{array}$ & $1,3,5,6,7,8,9,11$ & (Oh et al. 2004) \\
\hline$q S V-3-1 / 2,-5,-8-1 / 2$ & 2005 & Seedling growth & $3,5,8$ & (Zhang et al. 2005) \\
\hline qLVG2, qLVG7-2, aCIVG7-2 & 2006 & Vigor of germination & 2,7 & (Han et al. 2006) \\
\hline qCTS 12 & 2006 & Seedling growth & 12 & (Andaya and Tai 2006) \\
\hline qCTS4 & 2007 & Seedling growth & 4 & (Andaya and Tai 2007) \\
\hline aCTS-2 & 2007 & Seedling growth & 2 & (Lou et al. 2007) \\
\hline qLTG3-1 & 2008 & Vigor of germination & 3 & (Fujino et al. 2008) \\
\hline qCTB-1-1, $-4-1 / 2,-5-1 / 2,-10-1 / 2,-11-1$ & 2008 & Spikelet fertility & $1,4,5,10,11$ & (Xu et al. 2008) \\
\hline qCTP11, qCTP12 & 2009 & Vigor of germination & 11,12 & (Baruah et al. 2009) \\
\hline aPSST $-3,-7,-9$ & 2010 & Spikelet fertility/Growth in reproductive stage & $3,7,8,9,11$ & (Suh et al. 2010) \\
\hline Ctb1 & 2010 & Spikelet fertility/Undeveloped spikelet & 4 & (Saito et al. 2010) \\
\hline qCtss 11 & 2010 & Seedling growth & 11 & (Koseki et al. 2010) \\
\hline qCTB-5-1/2/3, -7 & 2010 & Vigor of germination & 5,7 & (Lin et al. 2010) \\
\hline qCTS4a, aCTS4b & 2012 & Seedling growth & 4 & (Suh et al. 2012) \\
\hline qLTB3 & 2012 & Seed fertility & 3 & (Shirasawa et al. 2012) \\
\hline
\end{tabular}

Using these RIL, Andaya and Mackill mapped a major QTL, $q C T S 12 a$, to chromosome 12 that accounted for $41 \%$ of the phenotypic variation in seedling growth after cold stress. A number of other QTL with smaller effects have also been detected on eight rice chromosomes (Andaya and Mackill 2003a). Using RM5746 and RM3103, Andaya and Tai screened $1954 \mathrm{~F}_{5}-\mathrm{F}_{10}$ lines to find recombinants in the $q$ CTS12 region. Additional microsatellite markers were identified from publicly available genomic sequences and used to fine map qCTS12 within a region of approximately $87 \mathrm{~kb}$ on the BAC clone OSJNBb0071I17. Subsequently, open reading frame analyses delimited the QTL to a region of about $55 \mathrm{~kb}$. The most likely candidates for the gene(s) underlying qCTS12 are OsGSTZ1 and OsGSTZ2 (Andaya and Tai 2006). OsGSTZ1 appears to function in improving cold tolerance at the germination stage, as overexpression of this gene in transgenic rice triggered enhanced germination and growth of seedlings at low temperature (Takesawa et al. 2002). Moreover, the qCTS4 locus, which is associated with tolerance to yellowing and stunting of rice seedlings, was mapped to chromosome 4 using the same RIL mapping population (Andaya and Tai 2007).

A set of $282 \mathrm{~F}_{13}$ RIL (recombinant inbred lines) derived by single-seed descent from a cross between 'Lemont' ( $j a-$ ponica) and 'Teqing' (indica) were used to map QTL controlling seedling vigor. A total of 34 QTL for seedling vigor were identified among these RIL. Of the QTL identified, the majority (82\%) clustered within five genomic regions, and these were designated $q S V-3-1, q S V-3-2, q S V-5$, $q S V-8-1$, and $q S V-8-2$, respectively (Zhang et al. 2005). A major QTL ( $\mathrm{LOD}=15.09)$, $q C T S-2$, was detected on chromosome 2 flanked by RM561 and RM341 in doubled haploid (DH) lines that were derived from a cross between a cold-tolerant japonica variety ('AAV002863') and a coldsensitive indica cultivar ('Zhenshan97B') (Lou et al. 2007). An $F_{2}$ population derived from a cold-tolerant wild relative of rice, W1943 (Oryza rufipogon), and a sensitive indica cultivar, 'Guang-lu-ai 4' (GLA4), were screened by seedling growth to identify QTL that control cold tolerance in rice. A major QTL for cold tolerance at the seedling stage, $q C$ tss 11 , was fine mapped to a $60 \mathrm{~kb}$ candidate region defined by markers AK24 and GP0030 on chromosome 11, in which six genes have been annotated. Expression analyses and resequencing of these six candidate genes indicated that the Os11g0615600 gene is expressed only from the GLA4 allele, and that the Os11g0615600 gene has a premature stop codon in the GLA4 haplotype. This suggests that either Os11g0615600 or Os11g0615900, or both, might control seedling cold tolerance in this population derived from the cross between W1943 and GLA4 (Koseki et al. 2010). Moreover, the deduced protein from the Os11g0615900 gene contains the NB-ARC (nucleotide-binding adaptor shared by APAF-1, R protein, and CED-4) domain, a conserved motif found in disease 
resistance proteins and involved in hypersensitive response (HR) (DeYoung and Innes 2006). The further functional studies of the Os11g0615900 gene under both cold stress and biotic stress would help to define the QTL $q C t s s 11$, and help discern whether the Os11g0615900 gene functions in crosstalk between biotic and abiotic stress. Therefore, these genes would be good candidate genes for future comparative functional analyses in cold-sensitive and cold-tolerant populations.

\section{QTL related to cold tolerance at the reproductive stage}

Many QTL related to cold tolerance at the reproductive stage have been identified in recent years. Saito and Miura detected two QTL, $C t b 1$ and $C t b 2$, on chromosome 4 using a set of near-isogenic lines (NIL) derived from the backcross 'Kirara397'/'Norin-PL8'/'Kirara397' (Saito et al. 2001). The QTL Ctb1 for cold tolerance as assessed by spikelet fertility was fine mapped to a $56 \mathrm{~kb}$ region (Saito et al. 2004). Moreover, Saito located Ctb1 within a $17 \mathrm{~kb}$ region and finally identified the first gene found to confer cold tolerance at the booting stage of rice. Based on a two-hybrid screen, Saito suggested that the F-box protein encoded by the $C t b 1$ gene functions as part of the E3 ubiquitin ligase complex (Saito et al. 2010). Other QTL related to cold tolerance at the booting stage as assessed by spikelet fertility, $q C T B 2 a$ and qCTB3, were mapped using 191 RIL derived from a cross between a temperate japonica rice variety, M-202, and a tropical indica variety, IR50 (Andaya and Mackill 2003b). QTL for Dth (days to heading), $c l$ (culm length), fer (spikelet fertility), pe (panicle neck exsertion), and $d c$ (discoloration) were identified among RIL developed from a cross between the indica cultivar, 'Milyang 23' and the japonica weedy rice, 'Hapcheonaengmi 3' (Oh et al. 2004). A set of NIL with cold tolerance at the booting stage have been developed by backcrossing the strongly cold-tolerant japonica landrace, 'Kunmingxiaobaigu' (KMXBG) to the cold-sensitive japonica cultivar, 'Towada', as the pollen recipient parent. Eight QTL based on variation in spikelet fertility, $q C T B-1-1, q C T B-$ 4-1, qCTB-4-2, qCTB-5-1, qCTB-5-2, qCTB-10-1, qCTB$10-2$ and $q C T B-11-1$, were mapped in this population on chromosomes 1, 4, 5, 10, and 11, respectively. All of the alleles for cold tolerance were contributed by KMXBG, and the marker intervals containing these QTL were narrowed to $0.6-5.6 \mathrm{cM}$ (Xu et al. 2008). QTL analysis with simple sequence repeat (SSR) markers and composite interval mapping has identified three main-effect QTL assessed by spikelet fertility and growth during the reproductive stage, including qPSST-3, qPSST-7, and qPSST-9, respectively, on chromosomes 3, 7, and 9. In addition, a new source of cold-tolerance measured by spikelet fertility, line IR66160-121-4-4-2, was used as the pollen donor parent in a cross with a cold-sensitive cultivar, 'Geumobyeo', to produce $153 \mathrm{~F}_{8}$ RIL for QTL analysis (Suh et al. 2010). Another QTL for cold tolerance, $q L T B 3$, was identified on the long arm of chromosome 3 from the cold-tolerant breeding line 'Ukei 840' in $\mathrm{F}_{2}$ and $\mathrm{BC}_{1} \mathrm{~F}_{2}$ populations from crosses between 'Ukei 840 ' and 'Hitomebore'. The cold tolerance of 'Ukei 840' is derived from the Chinese cultivar 'Lijiangxintuanheigu' (Shirasawa et al. 2012). Cold tolerance related to qLTB3 in these lines was assessed by seed fertility.

Taken together, QTL for cold tolerance have been detected in rice at the seedling stage (Andaya and Mackill 2003a; Zhang et al. 2005), booting stage (Xu et al. 2008), bud burst stage (Lin et al. 2010), and plumule stage (Baruah et al. 2009), suggesting that cold tolerance could be both developmentally regulated and growth-stage specific (Suh et al. 2012; Foolad and Lin 2001).

\section{Conclusions}

Systematic studies have been carried out to improve our understanding of the physiological and genetic basis of cold tolerance in rice, which will promote the development of rice cultivars with improved cold tolerance. Cold stress interferes with metabolism and initiates changes in various physiological properties of plants. In rice, these changes are part of the cold-sensing system that initiates the cold-responsive signaling network. Reduced chlorophyll content and fluorescence (Fv/Fm) triggered by cold stress indicate injury to photosynthesis, as increased ROS and MDA subsequently mediate cold damage and cold sensing. Soluble sugars, proline, and antioxidants then accumulate and protect rice plants from further damage. Moreover, measurements of these physiological properties can also be used to evaluate the extent of cold tolerance exhibited by various rice cultivars to identify genes controlling cold tolerance for breeding purposes.

Currently, there are many criteria for the evaluation of cold tolerance; but is there a "gold standard" among techniques for assessing cold tolerance of a specific rice cultivar? The appropriate technique may depend on a number of factors, so a strong correlation between the measured trait and the ultimately desired trait, whether survival or yield after cold stress, is very important. Although a decrease in fresh weight can indicate cold stress, water loss is not always an accurate indicator of cold stress, because plant variety, leaf area, and other stressors can also affect water content measurements. Visual evaluations of cold stress using the seedling growth scale are performed immediately after a $14 \mathrm{~d}$ cold treatment at $9^{\circ} \mathrm{C}$, while those using leaf growth are performed after $7 \mathrm{~d}$ of recovery from $9^{\circ} \mathrm{C}$ cold stress. These techniques, particularly the latter, can help make fine distinctions in cold tolerance between varieties or individuals. Seedling survival rate (\%) can be a more 
practical criterion for cold tolerance than germinationstage cold tolerance because seedlings are more likely to actually experience cold stress in the field. Seedling survival would also be useful for addressing the discrepancies between greenhouse- and field-based results. For sublethal cold stress, such as $4^{\circ} \mathrm{C}$ cold stress that merely slows growth but does not cause severe damage, new leaf emergence is a better choice for distinguishing the cold tolerance of lines stressed at $4^{\circ} \mathrm{C}$. But an important disadvantage of all germination- and seedling-stage assays is that they do not necessarily predict reproductivestage cold tolerance, or may do so in a variety-specific manner.

For selection of appropriate parents for cold tolerance breeding, evaluation of cold tolerance at the reproductive stage is important. And because it results in strong selection, the examination of spikelet fertility after CGC seems to be an ideal approach for improving cold tolerance relatively quickly. To identify cold-tolerance related QTL that operate at the reproductive stage, the examination of spikelet fertility after CDWI is particularly useful because it is conducted directly in the field. Mechanistic studies to evaluate metabolic parameters and enzyme activities can be valuable for researchers who are interested in the functional characterization of genes related to cold response, because changes in metabolism and enzyme activities are useful for revealing the role of genes that function in the cold-sensing and cold-response networks.

The development of molecular markers and linkage maps has allowed detection of many QTL related to cold tolerance at various growth stages. Most QTL have been identified in mapping populations derived from crosses between varieties or accessions derived from $O$. japonica and $O$. indica, and between cultivated rice and its wild relatives. The future application of these QTL to MAS will significantly accelerate the breeding of cold-tolerant rice for temperate environments and high-altitude areas. However, the gap between greenhouse research and field application is a major concern in cold tolerance research. To resolve this problem, more researchers are evaluating cold tolerance using criteria that are conduct directly in the field, such as spikelet fertility after CDWI, to identify cold-tolerance related QTL. Moreover, Suh and Jena used both greenhouse and direct field methods to cross-validate their results (Suh et al. 2010; Jena et al. 2012), a positive trend for cold tolerance research in rice. Furthermore, in order to characterize and confirm the function of QTL identified in the greenhouse, Saito and Koseki conduct expression analysis or transgenic studies of candidate genes (Saito et al. 2010; Koseki et al. 2010). These approaches help to validate the function of these QTL in cold-tolerance and are necessary before initiating selection. In addition to these QTL and molecular markers, the mapping populations that have been established and used in mapping projects are valuable tools that are directly useful in cold tolerance breeding. In the future, the integration physiological mechanistic studies of cold tolerance and QTL identification will accelerate the improvement of rice for the traits related to cold tolerance.

\begin{abstract}
Abbreviations
QTL: Quantitative trait loci; ROS: Reactive oxygen species;

MDA: Malondialdehyde; MAS: Molecular marker-assisted selection; EL: Electrolyte leakage; GC-MS: Gas chromatography-mass spectrometry; ABA: Abscisic acid; ABRE: ABA-responsive elements; ABF: ABRE-binding bZIP transcription factor; AsA: Ascorbic acid; GSH: Glutathione; POD: Peroxidase; SOD: Superoxide dismutase; CAT: Catalase; APX: Ascorbate peroxidase; CGC: Cold greenhouse cultivation; CDWI: Cold deep-water irrigation.
\end{abstract}

\section{Competing interests}

The authors declare that they have no competing interests.

\section{Authors' contributions}

QZ, QC, and SW performed the analysis, and prepared the figure and tables. $\mathrm{QZ}, \mathrm{YH}$, and ZW designed and wrote the paper. All authors read and approved the final manuscript.

\section{Acknowledgements}

This work was supported, in part, by grants from the National Transgenic Project (2012ZX08009001), the National 973 Project (2012CB723000), the National 863 Project (2014AA10A604), the National Natural Science Foundation of China (31071674, 31371927), the State Key Laboratory Breeding Base for Zhejiang Sustainable Pest and Disease Control (2010DS700124-KF1210), and the Hunan Province University Innovation Platform Open Fund Project (10 K031). ZW was also supported by the Program for Innovative Research Teams in University (IRT1239), the Aid Program for Science and Technology Innovative Research Team in Higher Educational Institutions of Hunan Province, the Hunan Provincial Key Laboratory for Crop Germplasm Innovation and Utilization (11KFXM01), and Hunan Agricultural University (11YJ13).

\section{Author details}

${ }^{1}$ Hunan Provincial Key Laboratory of Crop Germplasm Innovation and Utilization, College of Biological Science and Technology, College of Agronomy, Hunan Agricultural University, Changsha, Hunan 410128, China. ${ }^{2}$ Department of Anatomy and Neurobiology, Xiangya School of Medicine, Central South University, Changsha, Hunan 410013, China.

Received: 29 May 2014 Accepted: 9 September 2014

Published online: 02 October 2014

\section{References}

Andaya V, Mackill D (2003a) Mapping of QTLs associated with cold tolerance during the vegetative stage in rice. J Exp Bot 54(392):2579-2585

Andaya V, Mackill D (2003b) QTLs conferring cold tolerance at the booting stage of rice using recombinant inbred lines from a japonica $\times$ indica cross. Theor Appl Genet 106(6):1084-1090

Andaya V, Tai T (2006) Fine mapping of the aCTS12 locus, a major QTL for seedling cold tolerance in rice. Theor Appl Genet 113(3):467-475

Andaya VC, Tai TH (2007) Fine mapping of the qCTS4 locus associated with seedling cold tolerance in rice (Oryza sativa L.). Mol Breed 20(4):349-358

Apel K, Hirt H (2004) Reactive oxygen species: metabolism, oxidative stress, and signal transduction. Annu Rev Plant Biol 55:373-399

Baruah AR, Ishigo-Oka N, Adachi M, Oguma Y, Tokizono Y, Onishi K, Sano Y (2009) Cold tolerance at the early growth stage in wild and cultivated rice. Euphytica 165(3):459-470

Bonnecarrère V, Borsani O, Díaz P, Capdevielle F, Blanco P, Monza J (2011) Response to photoxidative stress induced by cold in japonica rice is genotype dependent. Plant Sci 180(5):726-732

Chinnusamy V, Zhu J, Zhu JK (2006) Gene regulation during cold acclimation in plants. Physiol Plant 126(1):52-61 
Chinnusamy V, Zhu J, Zhu JK (2007) Cold stress regulation of gene expression in plants. Trends Plant Sci 12(10):444-451

Cook D, Fowler S, Fiehn O, Thomashow MF (2004) A prominent role for the CBF cold response pathway in configuring the low-temperature metabolome of Arabidopsis. Proc Natl Acad Sci U S A 101(42):15243-15248

DeYoung BJ, Innes RW (2006) Plant NBS-LRR proteins in pathogen sensing and host defense. Nat Immunol 7(12):1243-1249

Fairhurst T, Dobermann A (2002) Rice in the global food supply. World 5 (7,502):454, 349-511,675

Foolad M, Lin G (2001) Genetic analysis of cold tolerance during vegetative growth in tomato, Lycopersicon esculentum Mill. Euphytica 122(1):105-111

Foolad M, Lin G, Chen F (1999) Comparison of QTLs for seed germination under non-stress, cold stress and salt stress in tomato. Plant Breed 118(2):167-173

Fujino K, Sekiguchi H, Matsuda Y, Sugimoto K, Ono K, Yano M (2008) Molecular identification of a major quantitative trait locus, aLTG3-1, controlling lowtemperature germinability in rice. Proc Natl Acad Sci U S A 105(34):12623-12628

Futsuhara Y, Toriyama K (1969) Genetic studies on cool tolerance in rice. IV. Direct and indirect effects of selection and cold tolerance. Jpn J Breed 19:286-292

Gothandam KM, Nalini E, Karthikeyan S, Shin JS (2010) OSPRP3, a flower specific proline-rich protein of rice, determines extracellular matrix structure of floral organs and its overexpression confers cold-tolerance. Plant Mol Biol 72(1):125-135

Haboudane D, Miller JR, Tremblay N, Zarco-Tejada PJ, Dextraze L (2002) Integrated narrow-band vegetation indices for prediction of crop chlorophyll content for application to precision agriculture. Remote Sens Environ 81 (2):416-426

Han LZ, Zhang YY, Qiao YL, Cao GL, Zhang SY, Kim JH, Koh HJ (2006) Genetic and QTL analysis for low-temperature vigor of germination in rice. Acta Genet Sin 33(11):998-1006

Hossain MA, Cho Jl, Han M, Ahn CH, Jeon JS, An G, Park PB (2010a) The ABREbinding bZIP transcription factor OSABF2 is a positive regulator of abiotic stress and ABA signaling in rice. J Plant Physiol 167(17):1512-1520

Hossain MA, Lee Y, Cho J-I, Ahn C-H, Lee S-K, Jeon J-S, Kang H, Lee C-H, An G, Park PB (2010b) The bZIP transcription factor OsABF1 is an ABA responsive element binding factor that enhances abiotic stress signaling in rice. Plant Mol Biol 72(4-5):557-566

Huang J, Sun SJ, Xu DQ, Yang X, Bao YM, Wang ZF, Tang HJ, Zhang H (2009) Increased tolerance of rice to cold, drought and oxidative stresses mediated by the overexpression of a gene that encodes the zinc finger protein ZFP245. Biochem Biophys Res Commun 389(3):556-561

Irri I (2002) Standard evaluation system for rice. International Rice Research Institute, Philippine

Ito Y, Katsura K, Maruyama K, Taji T, Kobayashi M, Seki M, Shinozaki K, YamaguchiShinozaki K (2006) Functional analysis of rice DREB1/CBF-type transcription factors involved in cold-responsive gene expression in transgenic rice. Plant Cell Physiol 47(1):141-153

Jena KK, Kim SM, Suh JP, Yang Cl, Kim YJ (2012) Identification of Cold-Tolerant Breeding Lines by Quantitative Trait Loci Associated with Cold Tolerance in Rice. Crop Sci 51(2):517-523

Kandpal RP, Rao NA (1985) Alterations in the biosynthesis of proteins and nucleic acids in finger millet (Eleucine coracana) seedlings during water stress and the effect of proline on protein biosynthesis. Plant Sci 40(2):73-79

Kanneganti V, Gupta AK (2008) Overexpression of OsiSAP8, a member of stress associated protein (SAP) gene family of rice confers tolerance to salt, drought and cold stress in transgenic tobacco and rice. Plant Mol Biol 66(5):445-462

Kim S-H, Choi H-S, Cho Y-C, Kim S-R (2011) Cold-Responsive Regulation of a Flower-Preferential Class III Peroxidase Gene, OsPOX1, in Rice (Oryza sativa L.). J Plant Biol 55(2):123-131

Kim S-I, Tai TH (2011) Evaluation of seedling cold tolerance in rice cultivars: a comparison of visual ratings and quantitative indicators of physiological changes. Euphytica 178(3):437-447

Kim SJ, Lee SC, Hong SK, An K, An G, Kim SR (2009) Ectopic expression of a coldresponsive OSAsr1 CDNA gives enhanced cold tolerance in transgenic rice plants. Mol Cells 27(4):449-458

Koseki M, Kitazawa N, Yonebayashi S, Maehara Y, Wang ZX, Minobe Y (2010) Identification and fine mapping of a major quantitative trait locus originating from wild rice, controlling cold tolerance at the seedling stage. Mol Genet Genomics 284(1):45-54

Krishnasamy V, Seshu D (1989) Seed germination rate and associated characters in rice. Crop Sci 29(4):904-908

Lee SC, Huh KW, An K, An G, Kim SR (2004) Ectopic expression of a coldinducible transcription factor, CBF1/DREB1b, in transgenic rice (Oryza sativa L.). Mol Cells 18(1):107-114
Lee SC, Kwon SY, Kim SR (2009) Ectopic expression of a cold-responsive CuZn superoxide dismutase gene, SodCCl, in transgenic rice (Oryza sativa L.). J Plant Biol 52(2):154-160

Lin J, Zhu W, Zhang Y, Zhu Z, Zhao L, Chen T, Zhao Q, Zhou L, Fang X, Wang Y (2010) Detection of quantitative trait loci for cold tolerance at the bud bursting stage by using chromosome segment substitution lines in rice (Oryza sativa). Chin J Rice Sci 24:233-236

Liu K, Wang L, Xu Y, Chen N, Ma Q, Li F, Chong K (2007) Overexpression of OsCOIN, a putative cold inducible zinc finger protein, increased tolerance to chilling, salt and drought, and enhanced proline level in rice. Planta 226 (4):1007-1016

Los DA, Murata N (2004) Membrane fluidity and its roles in the perception of environmental signals. Biochimica et Biophysica Acta (BBA)-Biomembranes 1666(1):142-157

Lou Q, Chen L, Sun Z, Xing Y, Li J, Xu X, Mei H, Luo L (2007) A major QTL associated with cold tolerance at seedling stage in rice (Oryza sativa L.). Euphytica 158(1):87-94

Ma Q, Dai X, Xu Y, Guo J, Liu Y, Chen N, Xiao J, Zhang D, Xu Z, Zhang X, Chong $K$ (2009) Enhanced tolerance to chilling stress in OSMYB3R-2 transgenic rice is mediated by alteration in cell cycle and ectopic expression of stress genes. Plant Physiol 150(1):244-256

Maruyama K, Urano K, Yoshiwara K, Morishita Y, Sakurai N, Suzuki H, Kojima M, Sakakibara H, Shibata D, Saito K (2014) Integrated analysis of the effects of cold and dehydration on rice metabolites, phytohormones, and gene transcripts. Plant Physiol 164(4):1759-1771

Matsunaga K (2005) Establishment of an evaluation method for cold tolerance at the booting stage of rice using deep water irrigation system and development of highly cold-tolerant rice varieties by combining cold tolerance genes. Bull Miyagi Furukawa Agric Exp Stn 4:1-78

McFarlane J, Watson R, Theisen A, Jackson RD, Ehrler W, Pinter P Jr, Idso SB, Reginato R (1980) Plant stress detection by remote measurement of fluorescence. Appl Opt 19(19):3287-3289

Mittal D, Madhyastha DA, Grover A (2012) Genome-Wide Transcriptional Profiles during temperature and oxidative stress reveal coordinated expression Patterns and overlapping regulons in rice. PLoS One 7(7):e40899

Mittler R (2002) Oxidative stress, antioxidants and stress tolerance. Trends Plant Sci 7(9):405-410

Morsy MR, Almutairi AM, Gibbons J, Yun SJ, De Los Reyes BG (2005) The OsLti6 genes encoding low-molecular-weight membrane proteins are differentially expressed in rice cultivars with contrasting sensitivity to low temperature. Gene 344:171-180

Morsy MR, Jouve L, Hausman JF, Hoffmann L, Stewart JMD (2007) Alteration of oxidative and carbohydrate metabolism under abiotic stress in two rice (Oryza sativa L.) genotypes contrasting in chilling tolerance. J Plant Physiol 164(2):157-167

Murata N, Los DA (1997) Membrane fluidity and temperature perception. Plant Physiol 115(3):875

Nagao M, Minami A, Arakawa K, Fujikawa S, Takezawa D (2005) Rapid degradation of starch in chloroplasts and concomitant accumulation of soluble sugars associated with ABA-induced freezing tolerance in the moss Physcomitrella patens. J Plant Physiol 162(2):169-180

Nakashima K, Takasaki H, Mizoi J, Shinozaki K, Yamaguchi-Shinozaki K (2012) NAC transcription factors in plant abiotic stress responses. Biochimica et Biophysica Acta (BBA)-Gene Regulatory Mechanisms 1819(2):97-103

Nakashima K, Tran LS, Van Nguyen D, Fujita M, Maruyama K, Todaka D, Ito Y, Hayashi N, Shinozaki K, Yamaguchi-Shinozaki K (2007) Functional analysis of a NAC-type transcription factor OsNAC6 involved in abiotic and biotic stressresponsive gene expression in rice. Plant J 51(4):617-630

Noctor G, Foyer CH (1998) Ascorbate and glutathione: keeping active oxygen under control. Annu Rev Plant Biol 49(1):249-279

Oh CS, Choi YH, Lee SJ, Yoon DB, Moon HP, Ahn SN (2004) Mapping of quantitative trait loci for cold tolerance in weedy rice. Breed Sci 54(4):373-380

Oliver SN, Van Dongen JT, Alfred SC, Mamun EA, Zhao X, Saini HS, Fernandes SF, Blanchard CL, Sutton BG, Geigenberger P (2005) Cold-induced repression of the rice anther-specific cell wall invertase gene OSINV4 is correlated with sucrose accumulation and pollen sterility. Plant Cell Environ 28(12):1534-1551

Pamplona R (2011) Advanced lipoxidation end-products. Chem-Biol Interact 192 (1):14-20

Saijo Y, Hata S, Kyozuka J, Shimamoto K, Izui K (2001) Over-expression of a single $\mathrm{Ca}^{2+}$-dependent protein kinase confers both cold and salt/drought tolerance on rice plants. Plant J 23(3):319-327 
Saito K, Hayano-Saito Y, Kuroki M, Sato Y (2010) Map-based cloning of the rice cold tolerance gene Ctb1. Plant Sci 179(1):97-102

Saito K, Hayano-Saito Y, Maruyama-Funatsuki W, Sato Y, Kato A (2004) Physical mapping and putative candidate gene identification of a quantitative trait locus Ctb 1 for cold tolerance at the booting stage of rice. Theor Appl Genet 109(3):515-522

Saito K, Miura K, Nagano K, Hayano-Saito Y, Araki H, Kato A (2001) Identification of two closely linked quantitative trait loci for cold tolerance on chromosome 4 of rice and their association with anther length. Theor Appl Genet 103(6):862-868

Sangwan V, Örvar BL, Beyerly J, Hirt H, Dhindsa RS (2002) Opposite changes in membrane fluidity mimic cold and heat stress activation of distinct plant MAP kinase pathways. Plant J 31(5):629-638

Satake T, Hayase H (1970) Male sterility caused by cooling treatment at the young micro-spore stage in rice plants. V. Estimations of pollen developmental stage and the most sensitive stage to coolness. Proc Crop Sci Soc Jpn 39 (4):468-473

Sato Y, Masuta Y, Saito K, Murayama S, Ozawa K (2011) Enhanced chilling tolerance at the booting stage in rice by transgenic overexpression of the ascorbate peroxidase gene, OsAPXa. Plant Cell Rep 30(3):399-406

Sato Y, Murakami T, Funatsuki H, Matsuba S, Saruyama H, Tanida M (2001) Heat shock-mediated APX gene expression and protection against chilling injury in rice seedlings. J Exp Bot 52(354):145-151

Schobert B, Tschesche H (1978) Unusual solution properties of proline and its interaction with proteins. Biochimica et Biophysica Acta (BBA)-General Subjects 541(2):270-277

Shah K, Dubey R (1997) Effect of cadmium on proline accumulation and ribonuclease activity in rice seedlings: role of proline as a possible enzyme protectant. Biol Plant 40(1):121-130

Shao HB, Guo QJ, Chu LY, Zhao XN, Su ZL, Hu YC, Cheng JF (2007) Understanding molecular mechanism of higher plant plasticity under abiotic stress. Colloids Surf B: Biointerfaces 54(1):37-45

Sharifi $P$ (2010) Evaluation on sixty-eight rice germplasms in cold tolerance at germination stage. Rice Sci 17(1):77-81

Sharma P, Sharma N, Deswal R (2005) The molecular biology of the lowtemperature response in plants. BioEssays 27(10):1048-1059

Shelton AM, Zhao J-Z, Roush RT (2002) Economic, ecological, food safety, and social consequences of the deployment of Bt transgenic plants. Annu Rev Entomol 47(1):845-881

Shimono H, Ishii A, Kanda E, Suto M, Nagano K (2011) Genotypic Variation in Rice Cold Tolerance Responses during Reproductive Growth as a Function of Water Temperature during Vegetative Growth All rights reserved. No part of this periodical may be reproduced or transmitted in any form or by any means, electronic or mechanical, including photocopying, recording, or any information storage and retrieval system, without permission in writing from the publisher. Permission for printing and for reprinting the material contained herein has been obtained by the publisher. Crop Sci 51(1):290-297

Shirasawa S, Endo T, Nakagomi K, Yamaguchi M, Nishio T (2012) Delimitation of a QTL region controlling cold tolerance at booting stage of a cultivar, 'Lijiangxintuanheigu', in rice, Oryza sativa L. Theor Appl Genet 124:937-946

Skopelitis DS, Paranychianakis NV, Paschalidis KA, Pliakonis ED, Delis ID, Yakoumakis DI, Kouvarakis A, Papadakis AK, Stephanou EG, RoubelakisAngelakis KA (2006) Abiotic stress generates ROS that signal expression of anionic glutamate dehydrogenases to form glutamate for proline synthesis in tobacco and grapevine. Plant Cell 18(10):2767-2781

Song SY, Chen Y, Chen J, Dai XY, Zhang WH (2011) Physiological mechanisms underlying OsNAC5-dependent tolerance of rice plants to abiotic stress. Planta 234(2):331-345

Suh J, Jeung J, Lee J, Choi Y, Yea J, Virk P, Mackill D, Jena K (2010) Identification and analysis of QTLs controlling cold tolerance at the reproductive stage and validation of effective QTLs in cold-tolerant genotypes of rice (Oryza sativa L.). Theor Appl Genet 120(5):985-995

Suh J, Lee C, Lee J, Kim J, Kim S, Cho Y, Park S, Shin J, Kim Y, Jena K (2012) Identification of quantitative trait loci for seedling cold tolerance using RILs derived from a cross between japonica and tropical japonica rice cultivars. Euphytica 184(1):101-108

Suzuki N, Mittler R (2006) Reactive oxygen species and temperature stresses: a delicate balance between signaling and destruction. Physiol Plant 126(1):45-51
Takesawa T, Ito M, Kanzaki H, Kameya N, Nakamura I (2002) Over-expression of $\zeta$ glutathione S-transferase in transgenic rice enhances germination and growth at low temperature. Mol Breed 9(2):93-101

Tian Y, Zhang H, Pan X, Chen X, Zhang Z, Lu X, Huang R (2011) Overexpression of ethylene response factor TERF2 confers cold tolerance in rice seedlings. Transgenic Res 20(4):857-866

Vannini C, Locatelli F, Bracale M, Magnani E, Marsoni M, Osnato M, Mattana M, Baldoni E, Coraggio I (2004) Overexpression of the rice Osmyb4 gene increases chilling and freezing tolerance of Arabidopsis thaliana plants. Plant J $37(1): 115-127$

Vaughan DA, Morishima H, Kadowaki K (2003) Diversity in the Oryza genus. Curr Opin Plant Biol 6(2):139-146

Venekamp JH (1989) Regulation of cytosol acidity in plants under conditions of drought. Physiol Plant 76(1):112-117

Xie G, Kato H, Imai R (2012) Biochemical identification of the OsMKK6-OsMPK3 signalling pathway for chilling stress tolerance in rice. Biochem J 443(1):95-102

Xie G, Kato H, Sasaki K, Imai R (2009) A cold-induced thioredoxin h of rice, OsTrx23, negatively regulates kinase activities of OsMPK3 and OsMPK6 in vitro. FEBS Lett 583(17):2734-2738

Xu LM, Zhou L, Zeng YW, Wang FM, Zhang HL, Shen SQ, Li ZC (2008) Identification and mapping of quantitative trait loci for cold tolerance at the booting stage in a japonica rice near-isogenic line. Plant Sci 174(3):340-347

Xu M, Li L, Fan Y, Wan J, Wang L (2011) ZmCBF3 overexpression improves tolerance to abiotic stress in transgenic rice (Oryza sativa) without yield penalty. Plant Cell Rep 30(10):1949-1957

Yamburenko MV, Zubo YO, Vanková R, Kusnetsov W, Kulaeva ON, Börner T (2013) Abscisic acid represses the transcription of chloroplast genes. J Exp Bot 64 (14):4491-4502

Yang A, Dai X, Zhang WH (2012) A R2R3-type MYB gene, OsMYB2, is involved in salt, cold, and dehydration tolerance in rice. J Exp Bot 63(7):2541-2556

Yuanyuan M, Yali Z, Jiang L, Hongbo S (2010) Roles of plant soluble sugars and their responses to plant cold stress. Afr J Biotechnol 8(10):2004-2010

Yun KY, Park MR, Mohanty B, Herath V, Xu F, Mauleon R, Wijaya E, Bajic VB, Bruskiewich R, de Los Reyes BG (2010) Transcriptional regulatory network triggered by oxidative signals configures the early response mechanisms of japonica rice to chilling stress. BMC Plant Biol 10:16

Zahedi H, Alahrnadi SMJ (2007) Effects of drought stress on chlorophyll fluorescence parameters, chlorophyll content and grain yield of wheat cultivars. J Biol Sci 7(6):841-847

Zhang J, Li J, Wang X, Chen J (2011a) OVP1, a vacuolar $\mathrm{H}^{+}$-translocating inorganic pyrophosphatase (V-PPase), overexpression improved rice cold tolerance. Plant Physiol Biochem 49(1):33-38

Zhang Q, Jiang N, Wang G-L, Hong Y, Wang Z (2013) Advances in understanding cold sensing and the cold-responsive network in rice. Adv Crop Sci Tech 1 (1):104

Zhang X, Guo X, Lei C, Cheng Z, Lin Q, Wang J, Wu F, Wang J, Wan J (2011 b) Overexpression of SICZFP1, a novel TFIIIA-type zinc finger protein from tomato, confers enhanced cold tolerance in transgenic Arabidopsis and rice. Plant Mol Biol Report 29(1):185-196

Zhang ZH, Qu XS, Wan S, Chen LH, Zhu YG (2005) Comparison of QTL controlling seedling vigour under different temperature conditions using recombinant inbred lines in rice (Oryza sativa). Ann Bot 95(3):423-429

Zhou L, Zeng Y, Hu G, Pan Y, Yang S, You A, Zhang H, Li J, Li Z (2012) Characterization and identification of cold tolerant near-isogenic lines in rice. Breed Sci 62(2):196

Zhu J, Dong CH, Zhu JK (2007) Interplay between cold-responsive gene regulation, metabolism and RNA processing during plant cold acclimation. Curr Opin Plant Biol 10(3):290-295

doi:10.1186/s12284-014-0024-3

Cite this article as: Zhang et al:: Rice and cold stress: methods for its evaluation and summary of cold tolerance-related quantitative trait loci. Rice 2014 7:24. 